\title{
Evaluation Studies of Private College Educational Efficiency Value-Added Performance
}

\author{
Xiao-yi LI* and Yue DENG \\ University of Sanya, Jiyang District, Sanya City, Hainan Province, 572000, China \\ ${ }^{*}$ Corresponding author
}

Keywords: Educational evaluation, Educational efficiency, Value-added.

\begin{abstract}
Educational efficiency is the contribution rate of education to individual development and national development. Traditional educational evaluation ignored the role of many factors, such as environments, students backgrounds and management ability. As an important measure to improve the evaluation system of private higher education, the evaluation of educational value-added as an educational performance is far more scientific and rational evaluation. The aim of this paper is to decompose evaluation of educational efficiency, which makes evaluation mechanism operational and feasible, timely monitoring the implementation effectiveness of private college education.
\end{abstract}

\section{Introduction}

Education efficiency is the core issue of education management theory, which has become an important factor in improving the relationship between educational performance and quality after continuous theoretical improvement and practical innovation. Educational efficiency, "the degree to which educational systems are successful in optimizing the educational inputloutput relationship"(UNESCO,1995),is one of the quality indicators available to the various stakeholders in the educational process. Institutions use data on the educational inputs and outputs as factors in quality assessment systems (Burnett \& Clarke,1999; Rovai,2003b). Government agencies use data on educational efficiency to allocate funds to learning porviders, such as universities(Yorke,1998). There're rather limited information available for leaners when deciding which study programme to follow (Simpson, 2004s)could be supplemented with efficiency data if it were more easily accessible. Educational efficiency enables educational organizations to fully realize characteristic and effective role of educational goals which reflects in the combination of the organization's potential functions and the explicit effect of organizational activities. The educational efficiencies can reflect the quality of education to some extent.

\section{Educational Efficiency Evaluation of Private Universities in China}

On the whole, the current evaluation methods for educational effectiveness in private universities in China are still relatively simple, and the rate of reform and innovation in educational evaluation is relatively slow. The main performance is that although each private college has established its own evaluation system, most colleges and universities still rely on students' comprehensive assessment data in terms of the content of the evaluation. Moreover, up till now, our country's college teachers have not really given up guidance and training in education evaluation. The evaluation of value-added education is based on the value of educational and teaching activities, which will increase the value of students.

However, in recent years, there have been significant increases in the number of students in non-governmental institutions of private higher learning. The scale of schools has also been rapidly expanding, and there has been little progress in student-appraisal methods. Therefore, there have been no major breakthroughs and innovations in the evaluation methods of the effectiveness of private college education. This leaves a lot of room for our research, which will briefly introduce the three mainstream student evaluation methods and their existing problems in the following. 


\section{Evaluation Method Rated by Comprehensive Test}

Comprehensive assessment is a quantitative analysis method. Nowadays, the content of comprehensive assessment in most private universities includes moral education, intellectual education, and sports education, such as the subjective inspection of ideological and moral, political attitudes; the objectivity test of academic achievement and scientific research ability; the examination of physical fitness and sports competition performance. Although the psychological quality of students is also very important, many of their projects can not be used as a standard for judging the merits of high and low scores, so the measurement results can not be included in the overall quality assessment of the project.

The comprehensive assessment method can more comprehensively evaluate the comprehensive development of students' morality, intelligence, and physical development. However, in practice, despite the efforts made by private university administrators to comprehensively evaluate the content and make the calculation method scientific, comprehensive assessment methods still have various shortcomings.

\section{Academic Evaluation Based on Academic Achievement}

The main means of evaluation of academic achievement is that teachers implement standardized tests and self-tests. Academic achievement evaluation is a process of value judgment of students' academic performance based on certain criteria. It is not only a test of student's academic achievement, but also a measure of teacher's teaching effect. According to the evaluation, students' learning defects can be found and teachers can find deficiencies in teaching.

Judging the student's academic achievement has a higher quality standard, including validity, reliability, difficulty, differentiation and so on. Generally speaking, the evaluation of students' academic achievement focuses on comprehensively examining: the breadth, depth, proficiency and completeness of the knowledge structure of the students; the speed, accuracy, innovation, and rationality of the questions; oral language organization ability, expression ability, logic and so on.

Incomplete Understanding. In addition to the basic management functions, students' academic achievement evaluation also derives a number of functions such as assessment, diagnosis, feedback, improvement, and motivation. However, in the specific implementation process, private colleges and universities only emphasized its management functions, only based on the test results to determine the quality of student learning, the selection of students, and other functions of academic achievement evaluation fail to attract enough attention.

Lack of Science. Among the many colleges and universities in China, only a few public courses, such as foreign languages, politics, and university languages, have national or university school entrance examinations, and most other subjects are taught by teachers freely. Many private colleges and universities do not have a unified curriculum syllabus and a specialized examination paper evaluation system, which has the difficulties of meeting the standardization requirements for most of the tests. At the same time, teachers have not received any special guidance or training on their own tests. The subjective arbitrariness of propositions is too large to guarantee the reliability, validity, difficulty and differentiation of self-test papers.

\section{The Mechanism of Evaluating Value-Added Education Efficiency in Private Universities}

\section{Investigation on Influencing Factors of Educational Efficiency}

In the current evaluation of higher education efficiencies, people are increasingly aware that the students' grown-up will be affected by many ways. In addition to its own factors, such as learning motivation and will, the growth of students are also influenced by external factors, such as the influence of schools and teachers, and the influence of families and the surrounding environment. Specifically, the influence of schools and teachers refers to the academic atmosphere of schools, the management abilities of school leaders, the level of teachers, etc.; and the influence of families and surrounding environments refers to the origins of students, family background, economic conditions, 
family structure, and Family relationships, parental qualifications, and occupations. In addition, the student's living environment, such as the family, and the student's living environment, such as the city where the school is located will also have a significant impact on students. Among these factors, there are many factors that schools and teachers cannot control.

Management Factor. In the survey, students were asked to estimate the importance of their academic factors. From the table1-1, it can be found that more than $80 \%$ of the interviewees think that the factors are important to the students' academic performance: the school's education level, the management level of the school leaders, and the teacher's ability to organize classes. Because these factors are related with management, we attribute them to management factors. In any group, the human factor is always the most important factor. The ability and level of the organizer plays a decisive role in the development of the collective. Therefore, in a school, the management level and ability of the leadership have a significant influence on the academic atmosphere, schooling level, and teaching style of the entire school; in a class, the teacher's organizational ability also affects the learning atmosphere and class of the entire class.

Table 1 . The influence of management factors on academic performance

\begin{tabular}{|c|c|c|c|}
\hline & Very important(\%) & General important(\%) & Unimportant(\%) \\
\hline Schooling capability & 90.8 & 4.7 & 2.0 \\
\hline Teachers' Organizational capability & 89.2 & 5.6 & 2.1 \\
\hline Leaders' management capability & 85.6 & 6.4 & 3.3 \\
\hline
\end{tabular}

Environmental Factor. As we all know, the environment shapes people and the environment will directly affect students' learning performance. For a student, the most important environment is the living environment that the family presents to him, and the learning environment that the school provides him. The family environment mainly includes the family structure, the family economic status, and the parent's occupation and education level. The survey found that three-quarters of private college students believe that the family economic situation will have a significant impact on learning, and more than half of college students believe that the level of parental education has an important impact on their own learning and employment. In contrast, only about a quarter of college students believe that family structure and parental career have a significant impact on learning and employment. Therefore, the most important factor in the family's environment should be the family's economic status and parents' education level(Table1-2). The student's school environment mainly includes the geographical location of the school, the nature of the school, the size of the school, the size of the class, the school's funding, and the school's curriculum(Table1-3). From the investigation, the school's funding and school curriculum have a more important impact on students' learning. More than $70 \%$ of the students in the survey think that the school's funding and school curriculum will affect learning and employment.

Table 2. The influence of family environment on learning and Employment

\begin{tabular}{|c|c|c|c|}
\hline & Very important(\%) & General important(\%) & Unimportant(\%) \\
\hline Family economic situation & 76.1 & 13.5 & 8.3 \\
\hline Parents' education level & 65.0 & 25.2 & 9.1 \\
\hline family structure & 20.2 & 40.8 & 29.5 \\
\hline Parental occupation & 24.6 & 40.6 & 30.4 \\
\hline
\end{tabular}

Table 3. The influence of learning environment on learning and Employment

\begin{tabular}{|c|c|c|c|}
\hline & Very important(\%) & General important(\%) & Unimportant(\%) \\
\hline Funding & 76.7 & 11.9 & 8.1 \\
\hline Course arrangement & 71.4 & 17.5 & 20.6 \\
\hline Scale of shcool & 35.2 & 40.1 & 22.7 \\
\hline Class size & 32.1 & 43.5 & 21.5 \\
\hline Location of school & 30.5 & 45.8 & \\
\hline
\end{tabular}

Teacher's Ability. The American scholar Saunders's researches also prove that there are significant differences between highly effective teachers and low-efficiency teachers from the 
perspective of promoting students' academic progress. For example, the freshmen who are at the lowest grade will be tested by the ability standards if they are taught by the most effective teachers in the next three years. In contrast, if they are taught by teachers with the lowest efficiency, they will only be able to meet the standard test of competence. Therefore, the teacher factor will have a very important impact on students' academic performance. From the work attitude, the teaching level, the titles and the academic qualifications of teachers, these factors affect students. In particular, the survey shows that the work attitude of teachers is almost considered by all students. Because attitudes determine height, if a competent teacher is not willing to devote himself to education, his teaching level is only a kind of decoration. In addition, the level of teaching is also considered by students . As regards the qualifications and titles of teachers, only a small number of students think that they will have an important impact on their own study or employment(Table1-4).

Table 4. The influence of teachers' ability on learning

\begin{tabular}{|c|c|c|c|}
\hline & Very important(\%) & General important(\%) & Unimportant(\%) \\
\hline Working attitudes & 71.3 & 15.5 & 11.4 \\
\hline Wording level & 56.7 & 25.3 & 15.1 \\
\hline Teachers' title & 28.2 & 40.8 & 29.7 \\
\hline Academic degreee & 29.7 & 35.2 & 30.6 \\
\hline
\end{tabular}

\section{Mathematical Model for Evaluation of Educational Efficiency Value-Added}

There are two main modes in the evaluation of the value-added education efficiency in Chinese private universities. One is to simply compare the average score, and the other is to calculate the added value by the traditional linear regression analysis.

\section{Limitations of Traditional Methods}

As the average score comparison method, it is to compare the average of a student's test scores as an evaluation index of the school or the class in order to compare the effeciencies of education in each school and each class. This method has obvious flaws in practice. From a computational point of view, the traditional regression model uses the conventional least squares method for parameter presetting. The basic model is

$$
\mathrm{Y}_{\mathrm{i}}=\mathrm{B}_{0}+\mathrm{B}_{1} \mathrm{Z}_{\mathrm{i}}+\mathrm{R}_{\mathrm{i}}
$$

$\mathrm{Y}_{\mathrm{i}}--$ Dependent variable; $\mathrm{Z}_{\mathrm{i}}--$ Independent variable; $\mathrm{B}_{0}-$ intercept; $\mathrm{B}_{1}--$ Regression coefficients; $\mathrm{R}_{\mathrm{i}}--$ Residual

\section{Advantages of the Multivariate Linear Model}

In the evaluation of value-added education efficiency in private colleges and universities, the data has a certain hierarchical relationship - students belong to the class, the class belongs to the school, and the school belongs to the educational administrative area. Only the multi-linear model can accurately represent the interlocking relationships among students, classes, and schools, which is undoubtedly the most suitable choice for college education efficiency measurement. The data has a hierarchical structure. we can consider two or more levels of influence factors only by the multivariate linear statistical model at the same time. When using multivariate linear models for analytical calculations, each level in the hierarchy can be represented by sub-models. These sub-models can not only reflect the relationship between the variables in this layer, but also define the impact of a certain level of variables on another level of variables, and test the corresponding hypotheses.

Basic multivariate linear model:

$$
\begin{aligned}
& Y_{i j}=B_{0 j} Z_{i j}+R_{i j} \\
& B_{0 j}=L_{00}+U_{0 j}
\end{aligned}
$$


$\mathrm{B}_{1 \mathrm{j}}=\mathrm{L}_{10}+\mathrm{U}_{1 \mathrm{j}}$

i---individual level $\mathrm{j}$-organizational level $\mathrm{L}_{00}$ and $\mathrm{L}_{10}$----the average of $\mathrm{B}_{0 \mathrm{j}}$ and $\mathrm{B}_{1 \mathrm{j}}$

$U_{0 j}$ and $U_{1 j}{ }^{----R a n d o m ~ c o m p o n e n t s ~ o f ~} B_{0 j}$ and $B_{1 j}$, Variance and covariance are as follows

$\mathrm{V}_{\mathrm{ar}}\left(\mathrm{U}_{\mathrm{oj}}\right)=\mathrm{T}_{00}$

$\mathrm{V}_{\mathrm{ar}}\left(\mathrm{U}_{1 \mathrm{j}}\right)=\mathrm{T}_{11}$

$\operatorname{Cov}\left(\mathrm{U}_{0 \mathrm{j}}, \mathrm{U}_{1 \mathrm{j}}\right)=\mathrm{T}_{01}$

Get( 3) and( 4 )equations into (2)

$\mathrm{Y}_{\mathrm{ij}}=\mathrm{L}_{00}+\mathrm{L}_{10} \mathrm{Z}_{\mathrm{ij}}+\left(\mathrm{U}_{\mathrm{oj}}+\mathrm{U}_{1 \mathrm{j}} \mathrm{Z}_{\mathrm{ji}}+\mathrm{R}_{\mathrm{ij}}\right)$

In fact, there are a series of models that can be used to set different individual level and organizational level parameters between the completely unconditional model and the complete model According to the purpose of the research and the actual situation, different variables can be added to each layer of equations, and different random components and fixed components can be set, thereby constructing various new and suitable analysis models.

\section{Conclusion}

\section{The Value-Added Assessment Method Can Quantify The Teaching Contribution to Schools}

The value-added evaluation method is regarded as the main method for evaluating private university educational efficiencies. It has the advantages of fairness, consistency, development, and clearer information. The evaluation of value-added education efficiencies is a new type of evaluation method that can quantify teaching effects. It is mainly because the performance of schools is easily reflected by quantitative scientific research indicators in the current evaluation system It is difficult to quantify the contribution of teaching work and the contribution to the value-added of school education. Therefore, with the aid of the evaluation results of value-added assessment methods, it is possible to solve the practical problems in the operation of universities that cannot be quantified.

\section{The Multivariate Linear Model is the Optimal Statistical Model for the Evaluation}

In the education evaluation, the multi-linear model is more objective, accurate, and effective than the average score comparison method and the traditional regression analysis. The multivariate linear model not only examines the correlation between school level and individual student-level influence factors, but also can test the homogeneity of the regression model. No matter what the criteria are to divide the results, it can provide an ideal solution. At present, there are several types of statistical analysis models in the evaluation of educational value-added. Although the methods of processing student data are not the same, it is clear that the multi-linear model has the best calculation effect and can achieve continuous interpretation of student achievement.

\section{Value-Added Assessment Allows Us to See the Net Impact of School Education}

The idea of value-added evaluation is to evaluate the net impact of the school on student growth. The growth of students not only has wise aspects, but also has many aspects such as morality, body, and beauty. In this paper, students' test scores were used to test the students' abilities, that is, they only did value-added evaluations of student intelligence. The growth of students is a polyhedron, so far there is no evaluation method that can make a comprehensive and real evaluation of the students' growth. It is hoped that with the enrichment of student information and the further improvement of people's consciousness. One day value-added assessment will become a method for comprehensive assessment. 


\section{Private Education Evaluation of Education Needs Further Research Direction}

First, in the evaluation of the value-added of education energy efficiency of private universities, the significant differences among the individuals affecting the value-added. In general, students in the same class will be less different than students in different classes, and students in the same school should be less different than students in different schools. If we can distinguish between the results of learning attitudes and the impact of teacher education, value-added evaluation methods are more popular. Second, it must also be observed that the value-added portion of the student's academic performance only shows the student's progress which is relative to the past, and cannot show his position which is relative to an external standard. A complete assessment should include both the results of value-added assessments and the results relative to external standards. Therefore, educational value-added assessment as a part of educational evaluation is also just one of the methods of educational evaluation. It can only be used as an aspect of many evaluations, and should not be used as the only evaluation criterion. Although the statistical analysis method used by the value-added assessment method is more complicated, the impact it brings to the education sector is enormous. The value-added assessment method should be coordinated with other education evaluation methods in order to make a comprehensive evaluation of the performance of students, teachers and universities.

\section{Acknowledgement}

This research was financially supported by Association of Social Sciences < Research on The Integration of College Artisan Spirit Education and Ideological and Political Education of University Students>(HNSZ2016-39).

\section{References}

[1] A.R. Napoli, L.A. Raymond. How Reliable Are Our Assessment Data: A Comparison of the Reliability of Data Produced in Graded and Un-Graded Conditions[J]. Reaearch in Higher Education.2004,(12).

[2] D. Ballou. Test Scalilng and Value-added Measurement[J].Education Finance And Policy.2009(04):351-383.

[3] B.Jacob, L. Lefgren. Can Principals Identify Effective Teachers? Evidence on Subjective Performance Evaluation in Education[J].Journal of Labor Economics.2008,(01):101-136.
[4] B.Froese.
Standardized
Testing+High-Stakes
Decisions=Educational Inequity[J].Interchange.2001,(06). 